Mini Review

\title{
Graphene-Based Composites for Electrochemical Sensor Fabrication and Their Application for Drug Detection
}

\author{
Wei Jiang $^{1 *}$, Lihua Huang ${ }^{2}$, Danli Zhang ${ }^{1}$, Yong Wang ${ }^{1}$, Guangyong Pan ${ }^{1}$ \\ ${ }^{1}$ School of Intelligent Manufacturing, Zhejiang Guangsha Vocational and Technical University of \\ Construction, Dongyang City, Zhejiang Province, 322100, P.R. China \\ ${ }^{2}$ School of Management Engineering, Zhejiang Guangsha Vocational and Technical University of \\ Construction, Dongyang City, Zhejiang Province, 322100, P.R. China \\ *E-mail: weijiang@sutcm.net
}

doi: $10.20964 / 2021.03 .69$

Received: 3 December 2020 / Accepted: 4 January 2021 / Published: 31 January 2021

\begin{abstract}
Rapid detection of drugs is very important in clinical and food safety. Electrochemical detection technology is an analytical technology suitable for rapid detection in the field. However, the performance of commercial electrodes limits the application of electrochemical sensors. Graphene has excellent electrochemical performance, and its composite materials often show better performance. In this review, we summarize the electrochemical sensors fabricated from graphene composites for drug detection between 2010 and 2020. From the review, we found that graphene can greatly improve the performance of electrochemical sensors. The improvement of this performance greatly accelerates the practical application potential of electrochemical sensors in drug detection.
\end{abstract}

Keywords: Graphene; Electrochemistry; Drug detection; Sensor; Nanocomposite

\section{$\underline{\text { FULL TEXT }}$}

(C) 2021 The Authors. Published by ESG (www.electrochemsci.org). This article is an open access article distributed under the terms and conditions of the Creative Commons Attribution license (http://creativecommons.org/licenses/by/4.0/). 